\title{
Virulent duck enteritis virus infected DEF cells generate a unique pattern of viral microRNAs and a novel set of host microRNAs
}

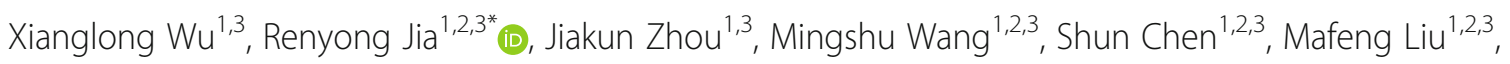
Dekang Zhu ${ }^{1,2,3}$, Xinxin Zhao ${ }^{1,2,3}$, Kunfeng Sun ${ }^{1,2,3}$, Qiao Yang ${ }^{1,2,3}$, Ying W $\mathbf{u}^{1,2,3}$, Zhongqiong Yin ${ }^{2}$, Xiaoyue Chen ${ }^{1,2}$, Jue Wang ${ }^{4}$ and Anchun Cheng ${ }^{1,2,3^{*}}$

\begin{abstract}
Background: Duck enteritis virus (DEV) belongs to the family Herpesviridae and is an important epornitic agent that causes economic losses in the waterfowl industry. The Chinese virulent (CHv) and attenuate vaccines (VAC) are two different pathogenic DEV strains. MicroRNAs (miRNAs) are a class of non-coding RNAs that regulate gene expression in viral infection. Nonetheless, there is little information on virulent duck enteritis virus (DEV)-encoded miRNAs.

Results: Using high-throughput sequencing, we identified 39 mature viral miRNAs from CHv-infected duck embryo fibroblasts cells. Compared with the reported 33 VAC-encoded miRNAs, only 13 miRNA sequences and 22 "seed sequences" of miRNA were identical, and 8 novel viral miRNAs were detected and confirmed by stem-loop RT-qPCR in this study. Using RNAhybrid and PITA software, $38 \mathrm{CHv}$-encoded miRNAs were predicted to target 41 viral genes and formed a complex regulatory network. Dual luciferase reporter assay (DLRA) confirmed that viral dev-miR-D8-3p can directly target the 3'-UTR of CHv US1 gene $(p<0.05)$. Gene Ontology analysis on host target genes of viral miRNAs were mainly involved in biological regulation, cellular and metabolic processes. In addition, 598 novel duckencoded miRNAs were detected in this study. Thirty-eight host miRNAs showed significant differential expression after CHv infection: 13 miRNAs were up-regulated, and 25 miRNAs were down-regulated, which may affect viral replication in the host cell.

Conclusions: These data suggested that CHv encoded a different set of microRNAs and formed a unique regulatory network compared with VAC. This is the first report of DEF miRNAs expression profile and an analysis of these miRNAs regulatory mechanisms during DEV infection. These data provide a basis for further exploring miRNA regulatory roles in the pathogenesis of DEV infection and contribute to the understanding of the CHv-host interaction at the miRNA level.
\end{abstract}

Keywords: Duck enteritis virus, MicroRNAs, Conservation, Pathogenesis, High-throughput sequencing

\footnotetext{
*Correspondence: jiary@sicau.edu.cn; chenganchun@vip.163.com

${ }^{1}$ Research Center of Avian Disease, College of Veterinary, Medicine of

Sichuan Agricultural University, Wenjiang District, Chengdu 611130, Sichuan

Province, China

Full list of author information is available at the end of the article
}

(C) The Author(s). 2018 Open Access This article is distributed under the terms of the Creative Commons Attribution 4.0 International License (http://creativecommons.org/licenses/by/4.0/), which permits unrestricted use, distribution, and reproduction in any medium, provided you give appropriate credit to the original author(s) and the source, provide a link to the Creative Commons license, and indicate if changes were made. The Creative Commons Public Domain Dedication waiver (http://creativecommons.org/publicdomain/zero/1.0/) applies to the data made available in this article, unless otherwise stated. 


\section{Background}

Duck viral enteritis, also called as duck plague, is an acute, contagious and fatal disease of duck and geese, resulting in considerable economic losses in the waterfowl breeding industry [1-4]. The causative agent of this disease is duck enteritis virus (DEV) which belongs to the species Anatid herpesvirus I, genus Mardivirus, subfamily Alphaherpesvirinae, family Herpesviridae [5]. Many countries, such as China, Britain, the United States, Germany, and Netherlands have reported the prevalence of this virus [6-8]. The genome of DEV is a linear double-stranded DNA molecule composed of a unique long region (UL) and a unique short region (US) flanked by an internal repeat sequence (IRS) and a terminal repeat sequence (TRS). Its genomic arrangement pattern (UL-IRS-US-TRS) is consistent with the members of Marek's disease virus 1 and 2 (MDV-1 and MDV-2), herpes simplex virus types 1 and 2 (HSV-1 and HSV-2) and Pseudorabies virus (PRV) [7, 8].

MicroRNAs (miRNAs) are small (18-24 nt), endogenous non-coding RNAs that widely found in plant, animal and viral genomes and are now increasingly recognized as important regulators of gene expression through post-transcriptional mechanisms, leading to mRNA degradation or translational inhibition by binding to fully or partially complementary 3 ' untranslated regions (3'UTR) [9]. These small miRNAs participate in a variety of biological processes, including cellular proliferation, differentiation, apoptosis, signal transduction and the process of virus-host interactions [10-14].

Over 300 virus-encoded miRNAs have been identified (miRBase 22.0). They were encoded by multiple virus families $[15,16]$, such as herpesviruses adenoviruses, polyomaviruses and retroviruses [17-19]. approximately $95 \%$ of viral miRNAs were encoded by herpesvirus families [20]. This phenomenon suggested the importance of miRNA-mediated gene regulation in the biology of herpesvirus infections. Some functions of viral miRNAs were validated by experiments in the pathogenesis of herpesvirus infection $[21,22]$.

As with many other miRNA-encoding $\alpha$-herpesviruses [23-28], DEV-encoded miRNAs were identified from VAC-infected chicken embryo fibroblast (CEF) by deep sequencing technology [29]. This research identified 24 pre-miRNAs in VAC genome producing 33 mature miRNAs. The VAC strain was attenuated and was widely used against duck viral enteritis [7], while the $\mathrm{CHv}$ strain (Chinese virulent DEV strain) can cause epidemical and fatal disease in waterfowl [30]. $\mathrm{CHv}$ and VAC are two different pathogenic DEV strains [31]. The mechanism of the two viruses causing different pathogenesis is not well understood. Our aim was to confirm whether the $\mathrm{CHv}$ encoded the same miRNAs as VAC and explore those miRNAs regulatory roles in $\mathrm{CHv}$ infection.
Moreover, recent studies have demonstrated that host miRNAs play crucial roles in viral infection $[20,21]$, but DEF-encoded miRNAs have not been reported until now. For the above purposes, we constructed and analysed the miRNA expression profile from $\mathrm{CHv}$-infected and uninfected DEF cells using high-throughput sequencing. The potential targets of viral and host miRNAs were predicted by RNAhybrid and PITA software. These data may contribute to the understanding of $\mathrm{CHv}$ pathogenesis and the $\mathrm{CHv}$ virus-host interaction at the overall miRNA level.

\section{Methods}

\section{Virus and cells}

CHv (GenBank accession No. JQ647509), a classic Chinese virulent strain, was isolated from an infected duck farm and kept in our laboratory. Primary duck embryo fibroblast (DEF) cells were made using 10-day-old embryonated duck eggs (Chengdu Egg \& Poultry Co. China) for virus propagation. The use of duck embryos in this study was approved by the Animal Ethics Committee of Sichuan Agricultural University (approval No. XF2014-18). Cell monolayers were cultured in Dulbecco's Modified Eagle's Medium (DMEM, Gibco, Grand Island, NY USA) supplemented with $8 \%$ foetal bovine serum (FBS, Gibco, USA) and $1 \%$ penicillinstreptomycin (Gibco, USA) at $37{ }^{\circ} \mathrm{C}$ in a $5 \% \mathrm{CO}_{2} \mathrm{hu}-$ midified incubator.

\section{Isolation and sequence of RNA}

Duck embryo fibroblasts (DEF) cells (80\% confluency per dish) were infected with $\mathrm{CHv}$ at a multiplicity of infection (MOI) of 1.0, with mock-infected DEF as a control. Cells were harvested at 2, 4, 6, 8, 12, 18, 24 and $30 \mathrm{~h}$ post-infection (hpi) and resuspended in TRIzol (TIANGEN, Beijing, China). Total RNAs from DEVinfected and uninfected DEF cells at the above time points were extracted according to the manufacturer's directions (TIANGEN, Beijing, China) and quantified using a NanoDrop 2000 Spectrophotometer (Thermo, Carlsbad, CA, USA). The RNA $(0.125 \mu \mathrm{g})$ extracted from the eight time points was mixed as a group. Our experiments were performed in triplicate and all the infected and control samples were subjected to Huada (Guangdong, China) for high-throughput sequencing of small RNAs (sRNAs). The same mixed RNA samples were used in the subsequent stem-loop RT-qPCR experiments.

\section{Data sources}

The CHv genome has been sequenced and the total size is $162,175 \mathrm{bp}$. The annotated VAC-encoded miRNAs were from miRBase 22.0 (http://www.mirbase.org/). Duck genomic sequences and the 3'UTR of duck genes were downloaded from the Ensembl database (http:// 
www.ensembl.org). The annotated chicken and Zebra Finch mature miRNAs were from miRBase 22.0 (http:// www.mirbase.org/).

\section{Analysis of viral small RNAs}

The total raw small RNA (sRNA) reads were detected by an Illumina Genome Analyser. The cleaned sequence reads were obtained after the filtering procedure as previously described [32, 33]. Using the Bowtie algorithm [34], the filtered sRNA reads were aligned to the known DEV pre-miRNA sequences in miRBase 22.0 with no mismatch and then aligned to the corresponding mature miRNA with at least 16 nts overlap allowing offsets. The known CHv-encoded miRNAs including the pre-miRNA sequences, length and count of reads would be obtained. The remaining sRNA reads mapped to genome were subjected for novel miRNA prediction. Mireap software (http://sourceforge.net/projects/mireap/) was used to predict novel miRNA by exploring the secondary structure. Dicer cleavage sites and predicted minimum free energies of unannotated sRNA reads.

\section{Analysis of host small RNAs}

There are not any Anas platyrhynchos miRNAs annotated in the miRBase 22.0. All host small RNA sequences were aligned with known mature miRNAs of two reference species (Gallus and Taeniopygia guttata) and Anas platyrhynchos genome by the Bowtie algorithm [34]. Different miRNA expression levels were normalized to get the number of transcripts per million (TPM) in two samples (CHv-infected and uninfected). Normalization formula: Normalized expression = Actual miRNA count/Total count of clean reads*1000000. A change of at least 2-fold between libraries was considered significant. Fold-change formula: Fold-change = $\log 2$ (treatment/control). $P$-value was set as the reported formula [35]. P-value $<0.05$ indicated significance differentially expressed miRNA.

\section{Target prediction and GO analysis of viral and host miRNAs}

Target genes of viral and host miRNAs were predicted using RNAhybrid and PITA software, and the parameters were strictly set as a previously reported program in the seed sequence [36]. The potential host target genes were analysed using the Gene Ontology (GO) program (http://www.geneontology.org). Gene Ontology enrichment analysis of the target genes was performed using Goseq [37] to detect the significantly enriched GO terms of the host target. The GO terms with $p<0$. 05 were considered significant. The WEGO software (http://wego.genomics.org.cn) was used to produce histograms of the GO annotations, including three fields: cellular component, biological process and molecular function.

\section{Stem-loop RT-qPCR}

The stem-loop RT-qPCR was conducted as previously described [36, 38]. Briefly, 1000 ng of RNA mixture were reverse-transcribed to cDNA and then $2 \mu \mathrm{L}$ cDNA was used for Real-time PCR amplification according to the company kit instructions (Thermo, Carlsbad, CA, USA). All primers used are listed in (Additional file 1: Table $\mathrm{S} 1$ ). The reaction conditions were as follows: reverse transcription was incubated at $50{ }^{\circ} \mathrm{C}$ for $45 \mathrm{~min}$ and kept at $85{ }^{\circ} \mathrm{C}$ for $5 \mathrm{~min}$. Next, real-time PCR was $95{ }^{\circ} \mathrm{C}$ for 5 min, 39 cycles of denaturing at $95{ }^{\circ} \mathrm{C}$ for $15 \mathrm{~s}$, annealing and extending $60{ }^{\circ} \mathrm{C}$ for $60 \mathrm{~s}$, and the cellular miRNA U6 was used as an internal control. The relative expression values were calculated using the comparative $2^{-\Delta \Delta \mathrm{Ct}}$ method [38].

\section{Vector constructs and luciferase assay}

The dev-miR-D8-3p mimic and negative control mimic (miR-NC) were synthesized by Ribobio (Guangzhou, China). The CHv US1 gene 3'UTR (nt 136,085-136,248) including the predicted dev-miR-D8-3p binding sites were synthesised and cloned into a pmirGLO vector (Promega, Madison, WI, USA) with SacI and XhoI sites and named pmirGLO-WT-US1, Accordingly, the mutant 3'UTR of the US1 vector was constructed and named pmirGLO-MU-US1. For luciferase assay, COS7 cells were seeded in 96-well plates and co-transfected with dev-miR-D8-3p mimic, miR-NC, pmirGLO-WT-US1 and pmirGLO-MU-US1 with Lipofectamine 3000 (Invitrogen, Carlsbad, CA, USA). We performed sitedirected dual luciferase reporter assay (DLRA), and luciferase activity was measured at $36 \mathrm{~h}$ posttransfection according to the manufacturer's protocol (Promega, Madison, WI, USA).

\section{Statistical analysis}

Each experiment was performed in triplicate and the data were presented as the means $(M) \pm$ standard deviations (SD) by the software GraphPad Prism (version7.0). The significance of the variability between different treatment groups was determined by one-way analysis of variance (ANOVA) tests of variance using the GraphPad Prism software (version 7.0). P-values $<0.05$ was considered statistically significant.

\section{Results}

\section{Analysis of sRNA libraries by deep sequencing}

In this study, we obtained 12,088,641 and 12,263,713 sRNA reads of 18-30 nucleotides from $\mathrm{CHv}$-infected and uninfected DEF cells. After filtering adapter sequences and low-quality sequences. 11,462,557 (94.82\%) 
and 11,836,099 (96.51\%) high quality reads from infected and uninfected sample were obtained, respectively. Among each sample, approximately $89.36 \%$ and $92.85 \%$ sRNAs ranged from 20 to 24 nt respectively, and most of the sRNA reads were $22 \mathrm{nt}$ in length (Fig. 1a). In addition to miRNAs, other noncoding sRNAs were also detected and categorized by following the priority rule: microRNA $($ miRNA $)>$ repeat $>$ rRNA $>$ tRNA > snoRNA > snRNA (Additional file 2: Table S2). Ultimately, 7,446,931 (64.97\%) and 7,995,424 (67.55\%) miRNA reads from $\mathrm{CHv}$-infected and uninfected libraries respectively were matched to the annotated miRNAs of VAC and the two reference species (Gallus gallus and Taeniopygia guttata), and remaining 3,158,331 (27.55\%) and 3,085,287 (26.07\%) unannotated sRNA reads from two libraries were matched to $\mathrm{CHv}$ and the duck genome for predicting novel miRNAs (Fig. 1b, c).

\section{Conservation analysis of miRNAs in CHv and VAC}

In our study, we obtained 29 pre-miRNAs (Additional file 3) and 39 mature miRNAs from the $\mathrm{CHv}$ strain by deep sequencing. The names, sequences, length and location of 39 mature miRNAs are listed in Table 1. Compared with previously reported 33 mature VAC-encoded miRNAs [29], 31 of 33 reported miRNAs were detected and were shown in Table 2. The remaining two miRNAs, dev-miR-D2-3p and dev-miR-D10-3p were not detected in our study. Among
31 detected miRNAs, only 13 miRNA sequences were identical, and 18 were different in contrast to VAC-encoded miRNAs (Table 2). Twenty-two miRNAs were identical in the "seed sequence" and the other 9 were not identical. The difference of the "seed sequence" mostly occurs in 28 nucleotides at the $5^{\prime}$ end of miRNAs. For example, dev-miR-D19-5p and dev-miR-D21-5p had one deleted base, dev-miR-D7-5p, dev-miR-D11-3p, devmiR-D13-5p, dev-miR-D14-3p and dev-miR-D23-3p had two deleted bases, the dev-miR-D4-3p had four deleted bases, and the dev-miR-D17-3p had three inserted bases. In addition, 8 novel $\mathrm{CHv}$-encoded miRNAs were identified and were named from devmiR-D25-5p to dev-miR-D31-3p (Table 1). The premiRNA hairpin structures and isoform expression profile of these novel miRNAs are shown in Additional file 3. Thirty-nine $\mathrm{CHv}$-encoded miRNAs were distributed mostly the unique long region (UL) and the repeat region (IRS and TRS) of the genome (Fig. 2). This result was consistent with the previous report about distribution of VAC-encoded miRNAs [29]. We found that 7 miRNAs were present in two copies, which were located in two loci in the $\mathrm{CHv}$ genome. Including dev-miRD20 to dev-miR-D24 (Table 1). Those miRNAs mapped in the internal repeat sequence (IRS) were marked as 'a' and the homologous miRNAs in terminal repeat sequences (TRS) were marked as 'b' (Fig. 2). including
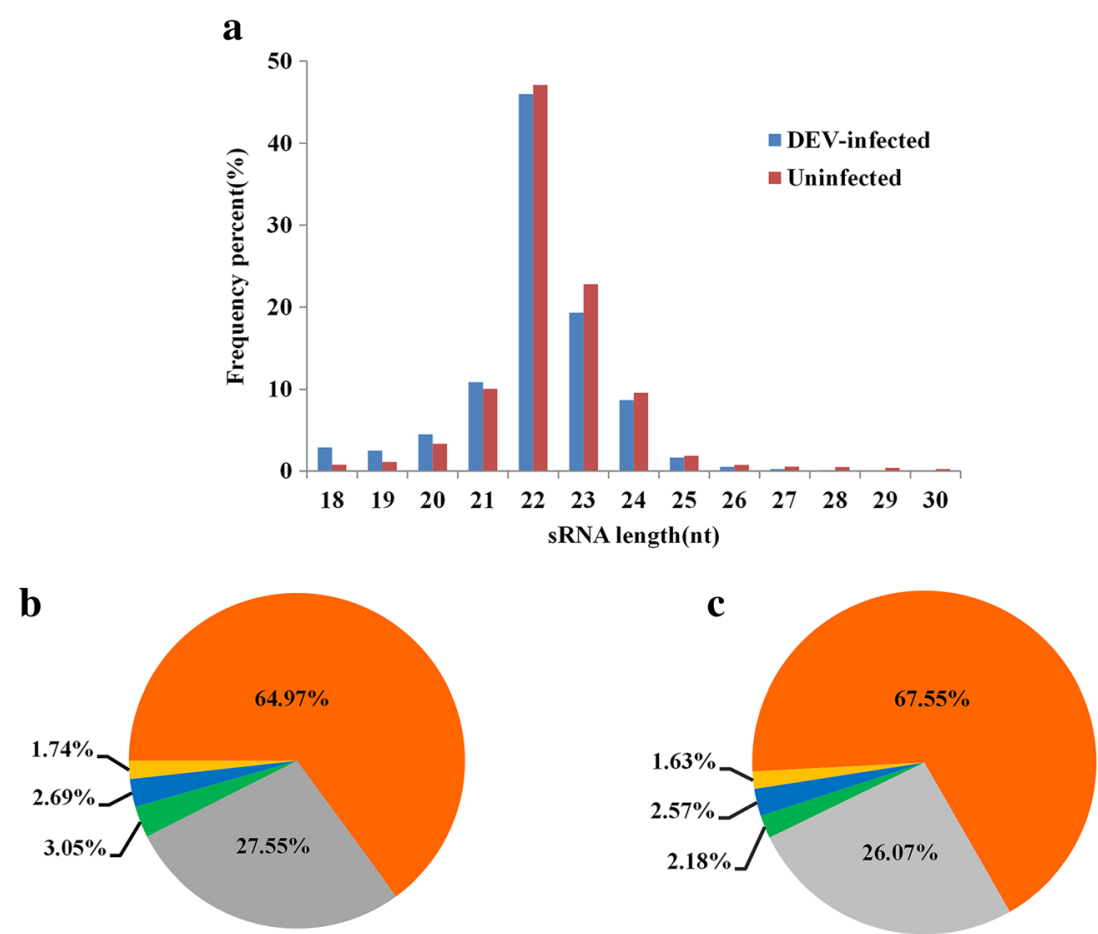

miRNA $=$ unannotated RNA $\mathbf{m}$ rRNA $=$ exon sense $=$ other

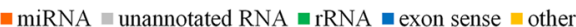

Fig. 1 Characterization of total sRNAs. a Length distributions of sRNAs (18-30 nt) in CHv-infected and uninfected DEF cells. b Pie chart summarizing the different classes of sRNAs in CHv-infected DEF cells. $\mathbf{c}$ Pie chart summarizing the different classes of sRNAs in uninfected DEF cells 
Table 1 Summary of sequence and genomic position of CHv-encoded miRNAs

\begin{tabular}{|c|c|c|c|c|}
\hline Name & Sequence $\left(5^{\prime}-3^{\prime}\right)$ & Length & Reads & Position and Strand \\
\hline dev-miR-D1-5p & UUGGGAAUGGCGGAAGAGCAGACU & 24 & 628 & 1328:1351 (-) \\
\hline dev-miR-D1-3p & UCCUCUUGCGCGAUCCCCACGU & 22 & 479 & 1294:1315 (-) \\
\hline dev-miR-D3-3p & AUUGUUGCGUUUGGUGGUUUGUG & 23 & 63 & $17,761: 17783(+)$ \\
\hline dev-miR-D4-3p & UUGUCGGAUUGGUAUGCUUU & 20 & 4 & $25,758: 25777(-)$ \\
\hline dev-miR-D5-5p & UGUCAUCUGCGACGUCCUGCUCG & 23 & 4157 & $52,654: 52676(-)$ \\
\hline dev-miR-D6-5p & UGACACACCACCAUUCUGGCCG & 22 & 904 & $53,728: 53749(-)$ \\
\hline dev-miR-D6-3p & GUCAGAGUGUCGGUGAGUCGA & 21 & 1018 & 53,695:53715 (-) \\
\hline dev-miR-D7-5p & CGUAGCGGCGUAUAAUGGUUU & 21 & 20 & $68,655: 68675(+)$ \\
\hline dev-miR-D8-5p & UGCCUCCCGAUUAAACUAUACG & 22 & 12 & $72,347: 72368(-)$ \\
\hline dev-miR-D8-3p & UACAGUUUCGUUGGGCGGUUU & 21 & 18,987 & $72,309: 72329(-)$ \\
\hline dev-miR-D9-5p & CGUUUGAACGUUCUGUACUGCC & 22 & 12,713 & $72,498: 72519(-)$ \\
\hline dev-miR-D9-3p & CAGUCCAGAAUGUUCAAAC & 19 & 1680 & $72,458: 72476(-)$ \\
\hline dev-miR-D11-3p & AAAAGGGCAGCCUGGGCU & 18 & 1 & $75,095: 75112(+)$ \\
\hline dev-miR-D12-5p & UACCUGGGACAGAACCGCGGCCG & 23 & 15,960 & 79,299:79321 (-) \\
\hline dev-miR-D12-3p & CUCCGCGGUGAGGUCCCAGAA & 21 & 870 & $79,263: 79283(-)$ \\
\hline dev-miR-D13-5p & CGUGGGGUAGAACGCAUG & 18 & 14 & 105,693:105710 (-) \\
\hline dev-miR-D14-3p & GUUAUGUCUGGUUAUUAUGUUUU & 23 & 1 & 107,259:107281 (-) \\
\hline dev-miR-D15-3p & CGAGCGUGGGCAAGGUACC & 19 & 700 & 112,570:112588 (-) \\
\hline dev-miR-D16-3p & CUAAACACCAACGGAUGAACGU & 22 & 14,930 & 112,727:112748 (-) \\
\hline dev-miR-D17-5p & UGCAACGAAGGCGAACGGUUGA & 22 & 5191 & 117,132:117153 (-) \\
\hline dev-miR-D17-3p & UCCGACCGCUCGCCUUCGAGGC & 22 & 3 & 117,098:117119 (-) \\
\hline dev-miR-D18-5p & GGGAUCGGUGAGGGGGGAUUGUG & 23 & 2676 & 119,157:119179(-) \\
\hline dev-miR-D18-3p & CCAUCCCCUCCGCUGGCCCCAA & 22 & 1819 & 119,119:119140 (-) \\
\hline dev-miR-D19-5p & AUGAAAGAGCGGUGCCUUU & 19 & 771 & 119,180:119198 (-) \\
\hline dev-miR-D20-5p & AAUGUCGGCCAGCCUCUCCGCUU & 23 & 11,422 & $125,008: 125030(+) / 160,535: 160557(-)$ \\
\hline dev-miR-D21-5p & GGUUUGGAGACAGCUGCGGUGG & 22 & 651 & $125,178: 125199(+) / 160,366: 160387(-)$ \\
\hline dev-miR-D21-3p & AUCCAUGCAAUCUCCAAACAAC & 22 & 347 & $125,218: 125239(+) / 160,326: 160347(-)$ \\
\hline dev-miR-D22-5p & UUACCCGCCCAUGCGUGACUGCC & 23 & 2201 & $126,494: 126516(+) / 159,049: 159071(-)$ \\
\hline dev-miR-D22-3p & GUCACACAAGGCGGCUAGCAGG & 22 & 11 & 126,532:126553 (+)/159,012:159033(-) \\
\hline dev-miR-D23-3p & CGAACCGUCACAGUCUGCAGA & 21 & 3322 & $128,060: 128080(+) / 157,485: 157505(-)$ \\
\hline dev-miR-D24-3p & AUUGGCUUCAGAGUGCGAACGC & 22 & 21 & 134,514:134535 (+)/151,030:151051(-) \\
\hline dev-miR-D25-5p & UGUGGGGACCGUGUAUGAGAUGU & 23 & 145 & $696: 718(-)$ \\
\hline dev-miR-D26-5p & AUCGAAGCGAGGCGAGAUAACCU & 23 & 12 & $26,368: 26390(-)$ \\
\hline dev-miR-D26-3p & GUUCUCCCUUGCUUUGACAU & 20 & 12 & $26,329: 26348(-)$ \\
\hline dev-miR-D27-5P & AUCCUGGACCGAUAUAUGGACA & 22 & 197 & $73,467: 73488(-)$ \\
\hline dev-miR-D28-3P & CUGGUGGGAAGAAUUUUCGC & 20 & 149 & $77,133: 77152(-)$ \\
\hline dev-miR-D29-5p & AACAUAUCUCUUGACCUCUGGCGU & 24 & 2323 & $87,039: 87062(-)$ \\
\hline dev-miR-D30-3P & ACUGGCUGGGGUGCAACUAAGU & 22 & 9 & 103,962:103983 (-) \\
\hline dev-miR-D31-3p & AUCACGGGGUGUUAGAUGAACC & 22 & 13,664 & $123,167: 123188(+)$ \\
\hline
\end{tabular}

dev-miR-D20a/b-5p, dev-miR-D21a/b-3P, dev-miRD21a/b-5p dev-miR-D22a/b-3p, dev-miR-D22a/b-5P, dev-miR-D23a/b-3p and dev-miR-D24a/b-3p. This "two-copy" phenomenon seems to be a common feature in $\alpha$-herpesviruses.

\section{Self-regulation analysis of viral miRNAs}

Prediction results showed that 41 viral genes were targeted by 38 viral miRNAs. Some novel viral miRNAs (like dev-miR-D27-5p and dev-miR-D28-3p) could target multiple $\mathrm{CHv}$ genes, and the some $\mathrm{CHv}$ genes (like 
Table 2 The differences (D) or similarities (S) between the known viral miRNAs from CHv and VAc strain (miRBase)

\begin{tabular}{|c|c|c|c|c|}
\hline Name & $\mathrm{CHv}$-Seq $\left(5^{\prime}-3^{\prime}\right)$ & Vac-Seq $\left(5^{\prime}-3^{\prime}\right)$ & Seq(S/D) & Seed Seq(S/D) \\
\hline dev-miR-D1-3p & UCCUCUUGCGCGAUCCCCACGU & UCCUCUUGCGCGAUCCCCACGU & S & $S$ \\
\hline dev-miR-D1-5p & UUGGGAAUGGCGGAAGAGCAGACU & UUGGGAAUGGCGGAAGAGCAGACU & S & S \\
\hline dev-miR-D3-3p & AUUGUUGCGUUUGGUGGUUUGUG & AUUGUUGCGUUUGGUGGUUUGUG & S & S \\
\hline dev-miR-D4-3p & UUGUCGGAUUGGUAUGCUUU & UUAAUUGUCGGAUUGGUAUGCUUUUU & $\mathrm{D}$ & $D$ \\
\hline dev-miR-D5-5p & UGUCAUCUGCGACGUCCUGCUCG & UGUCAUCUGCGACGUCCUGCUCG & S & $s$ \\
\hline dev-miR-D6-3p & GUCAGAGUGUCGGUGAGUCGA & GUCAGAGUGUCGGUGAGUCGACG & $\mathrm{D}$ & S \\
\hline dev-miR-D6-5p & UGACACACCACCAUUCUGGCCG & UGACACACCACCAUUCUGGCCG & S & $s$ \\
\hline dev-miR-D7-5p & CGUAGCGGCGUAUAAUGGUUU & UUCGUAGCGGCGUAUAAUGGUUU & $\mathrm{D}$ & $D$ \\
\hline dev-miR-D8-3p & UACAGUUUCGUUGGGCGGUUU & UACAGUUUCGUUGGGCGGUUUC & $\mathrm{D}$ & $S$ \\
\hline dev-miR-D8-5p & UGCCUCCCGAUUAAACUAUACG & UGCCUCCCGAUUAAACUAUACGC & $\mathrm{D}$ & $S$ \\
\hline dev-miR-D9-3p & CAGUCCAGAAUGUUCAAAC & CAGUCCAGAAUGUUCAAACG & $\mathrm{D}$ & $S$ \\
\hline dev-miR-D9-5p & CGUUUGAACGUUCUGUACUGCC & CGUUUGAACGUUCUGUACUGCCC & $\mathrm{D}$ & S \\
\hline dev-miR-D11-3p & AAAAGGGCAGCCUGGGCU & GCAAAAGGGCAGCCUGGGCUCUAU & D & $D$ \\
\hline dev-miR-D12-3p & CUCCGCGGUGAGGUCCCAGAA & CUCCGCGGUGAGGUCCCAGAAA & $\mathrm{D}$ & $S$ \\
\hline dev-miR-D12-5p & UACCUGGGACAGAACCGCGGCCG & UACCUGGGACAGAACCGCGGCCG & S & $s$ \\
\hline dev-miR-D13-5p & CGUGGGGUAGAACGCAUG & CCCGUGGGGUAGAACGCAU & $\mathrm{D}$ & $D$ \\
\hline dev-miR-D14-3p & GUUAUGUCUGGUUAUUAUGUUUU & GCGUUAUGUCUGGUUAUUAUGUUUUU & $\mathrm{D}$ & $D$ \\
\hline dev-miR-D15-3p & CGAGCGUGGGCAAGGUACC & CGAGCGUGGGCAAGGUACCAG & $\mathrm{D}$ & $S$ \\
\hline dev-miR-D16-3p & CUAAACACCAACGGAUGAACGU & CUAAACACCAACGGAUGAACGU & S & $S$ \\
\hline dev-miR-D17-3p & UCCGACCGCUCGCCUUCGAGGC & GACCGCUCGCCUUCGAGGCCACC & D & $D$ \\
\hline dev-miR-D17-5p & UGCAACGAAGGCGAACGGUUGA & UGCAACGAAGGCGAACGGUUG & $\mathrm{D}$ & $s$ \\
\hline dev-miR-D18-3p & CCAUCCCCUCCGCUGGCCCCAA & CCAUCCCCUCCGCUGGCCCCAA & S & $S$ \\
\hline dev-miR-D18-5p & GGGAUCGGUGAGGGGGGAUUGUG & GGGAUCGGUGAGGGGGGAUUGUG & $S$ & $s$ \\
\hline dev-miR-D19-5p & AUGAAAGAGCGGUGCCUUU & GAUGAAAGAGCGGUGCCUUU & $\mathrm{D}$ & $D$ \\
\hline dev-miR-D20-5p & AAUGUCGGCCAGCCUCUCCGCUU & AAUGUCGGCCAGCCUCUCCGCUU & $\mathrm{S}$ & S \\
\hline dev-miR-D21-3p & AUCCAUGCAAUCUCCAAACAAC & AUCCAUGCAAUCUCCAAACAACC & $\mathrm{D}$ & S \\
\hline dev-miR-D21-5p & GGUUUGGAGACAGCUGCGGUGG & UGGUUUGGAGACAGCUGCGGUGGU & $\mathrm{D}$ & $D$ \\
\hline dev-miR-D22-3p & GUCACACAAGGCGGCUAGCAGG & GUCACACAAGGCGGCUAGCAGG & $\mathrm{S}$ & $s$ \\
\hline dev-miR-D22-5p & UUACCCGCCCAUGCGUGACUGCC & UUACCCGCCCAUGCGUGACUGCC & S & S \\
\hline dev-miR-D23-3p & CGAACCGUCACAGUCUGCAGA & CGCGAACCGUCACAGUCUGCAG & $\mathrm{D}$ & $D$ \\
\hline dev-miR-D24-3p & AUUGGCUUCAGAGUGCGAACGC & AUUGGCUUCAGAGUGCGAACGC & S & $S$ \\
\hline dev-miR-D2-3p ${ }^{b}$ & & AUAAGGCGAUCCGUGGUUU & & \\
\hline dev-miR-D10-3p ${ }^{b}$ & & CUUUGAGUUCUAGCCCGUCUAUC & & \\
\hline
\end{tabular}

${ }^{\mathrm{a}}$ Seed sequence of miRNAs were present in italic font

${ }^{\mathrm{b}}$ The dev-miR-D2-3p and dev-miR-D10-3p were not detected in CHv-infected DEF cells

UL24, UL28 and UL52) could be targeted by multiple viral miRNAs. A complex regulatory network was formed according to the regulation interaction between viral miRNAs and target genes (Additional file 4: Figure S2).

\section{Regulatory analysis of viral miRNAs on host genes}

Analysis results showed that the 3'UTRs of 4703 host genes were targeted by 39 viral miRNAs using the intersection of the two software programs (Additional file 5: Table S3). Gene Ontology (GO) annotation was performed to analyze biological function of the host target genes. The results reflected that these host target genes were mainly concentrated in the cellular process, metabolic process, signal-organism process, biological regulation process and others (Additional file 6: Table S4). Among of these host target genes, GO enrichment analysis showed that 236 genes were related to signaling processes $(p<0.05)$ and 66 genes were related to immune system processes $(p<0.05)$ (Fig. 3, Additional file 6: Table S4), which implied that viral miRNAs may play important regulatory function during viral infection and immune evasion. 
$\operatorname{DEV}(\mathrm{CHv}) \quad 162,175(\mathrm{bp})$
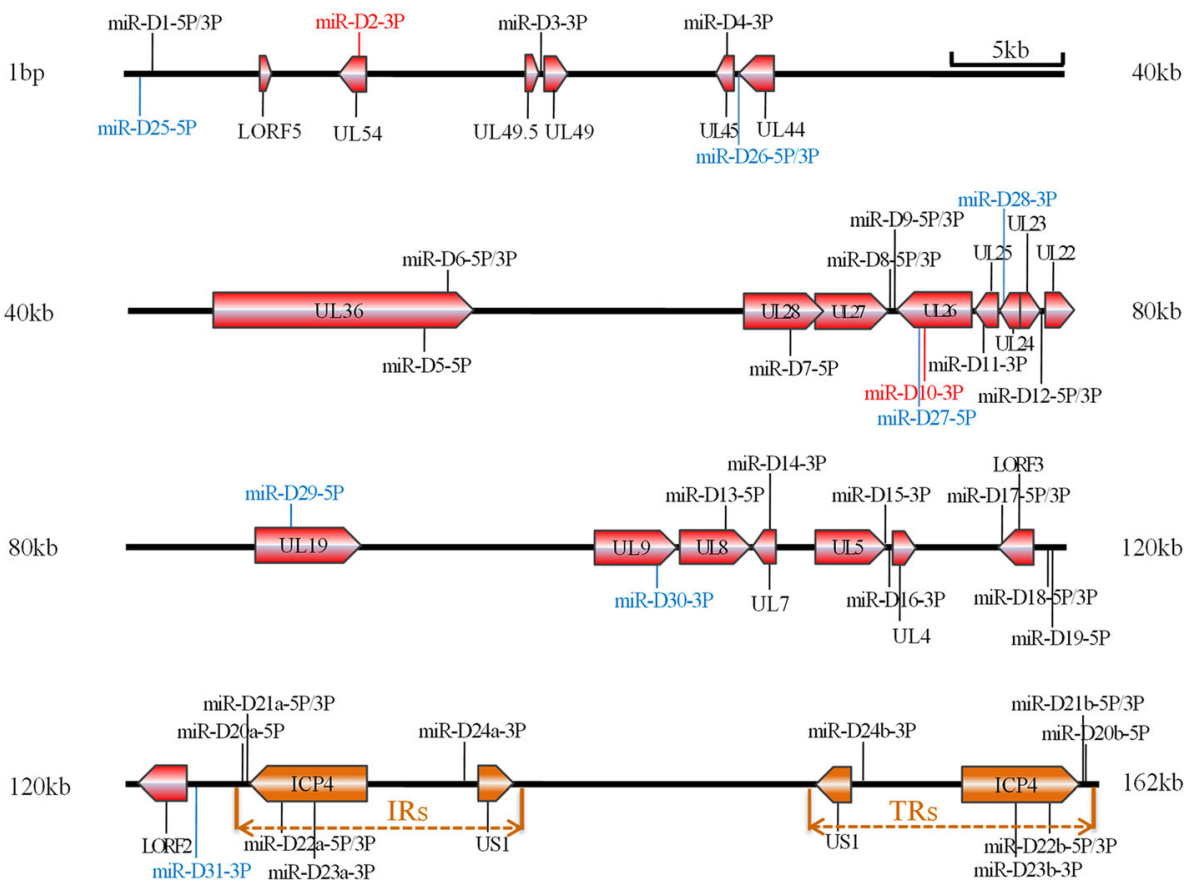

Fig. 2 Location of virus-encoded mature miRNAs in the CHv genome. The relative positions of the known and predicted novel miRNAs in the $\mathrm{CH} v$ genome are shown. The linear form indicated DEV CHv genome. The orientations of each of the ORFs in relation to the miRNA location were indicated with red or orange arrows. The internal repeat sequences (IRs) and terminal repeat sequences (TRs) of DEV CHv genome were indicated with orange. The undetected miRNAs were indicated with red font. The known miRNAs were indicated with black font and the novel miRNAs were indicated with blue font

\section{Expression and differential analysis for host miRNAs}

Alignment results showed that 598 mature host miRNAs were detected in this study (Fig. 4a). Among these, 386 (64.5\%) miRNAs (264 aligned and 122 novel) were coexpressed in both libraries (Additional file 7: Table S5), 108 (18.1\%) miRNAs were unique to the DEV-infected group and $104(17.4 \%)$ miRNAs were unique to the uninfected group (Additional file 8: Table S6). Among the co-expressed host miRNAs, 38 miRNAs were differentially expressed between the $\mathrm{CHv}$-infected sample and uninfected sample (Additional file 9: Table S7). Thirteen were significantly up-regulated and 25 were significantly down-regulated after $\mathrm{CHv}$ infection (Fig. 4b). Thirtyeight differentially expressed host miRNAs were predicted to target viral genes using the RNAhybrid and PITA software, and the results showed that the 3'UTRs of 40 viral genes were targeted by 36 host miRNAs by the intersection of two software (Additional file 10: Figure S3).

\section{Stem-loop RT-qPCR for miRNAs confirmation}

To further validate deep sequencing results, 8 novel viral miRNAs and 10 randomly differentially expressed host miRNAs were confirmed using stem-loop RT-qPCR. The results obtained by RT-qPCR were highly consistent with the deep sequencing data (Fig. 4c, d).

\section{Dev-miR-D8-3p target the 3'UTR of US1 gene}

Dual luciferase reporter assay (DLRA) showed that the luciferase level of the pmirGLO-WT-US1 was significantly repressed by dev-miR-D8-3p compared to the negative control miR-NC ( $<<0.05)$ (Fig. 5a, b). To further ascertain that the down-regulation of targets by dev-miR-D8-3p is binding sites dependent, the binding sites of US1 were mutated and constructed as pmirGLO-MU-US1 vector (Fig. 5a). As expected, the dev-miR-D8-3p lost its repression effect on the mutant vector of pmirGLO-MU-US1. These results indicated that the dev-miR-D8-3p can directly target the CHv US1 gene by 7 nucleotide complementary seed sequence.

\section{Discussion}

Previous research has reported that the VAC encoded 33 mature miRNAs in the viral genome [29]. We obtained 39 mature viral miRNAs from $\mathrm{CHv}$-infected DEF cells, 22 of $39 \mathrm{CHv}$-encoded miRNAs share identical "seed sequence" with VAC-encoded miRNAs. Another $17 \mathrm{miR}$ NAs (9 different "seed sequence" miRNAs and 8 novel miRNAs) were different in the "seed sequence". As we know, target-gene recognition of viral miRNA is strictly dependent on the full base complementarity of the "seed sequence", which covered 2 to 8 nucleotides from the 5 ' 


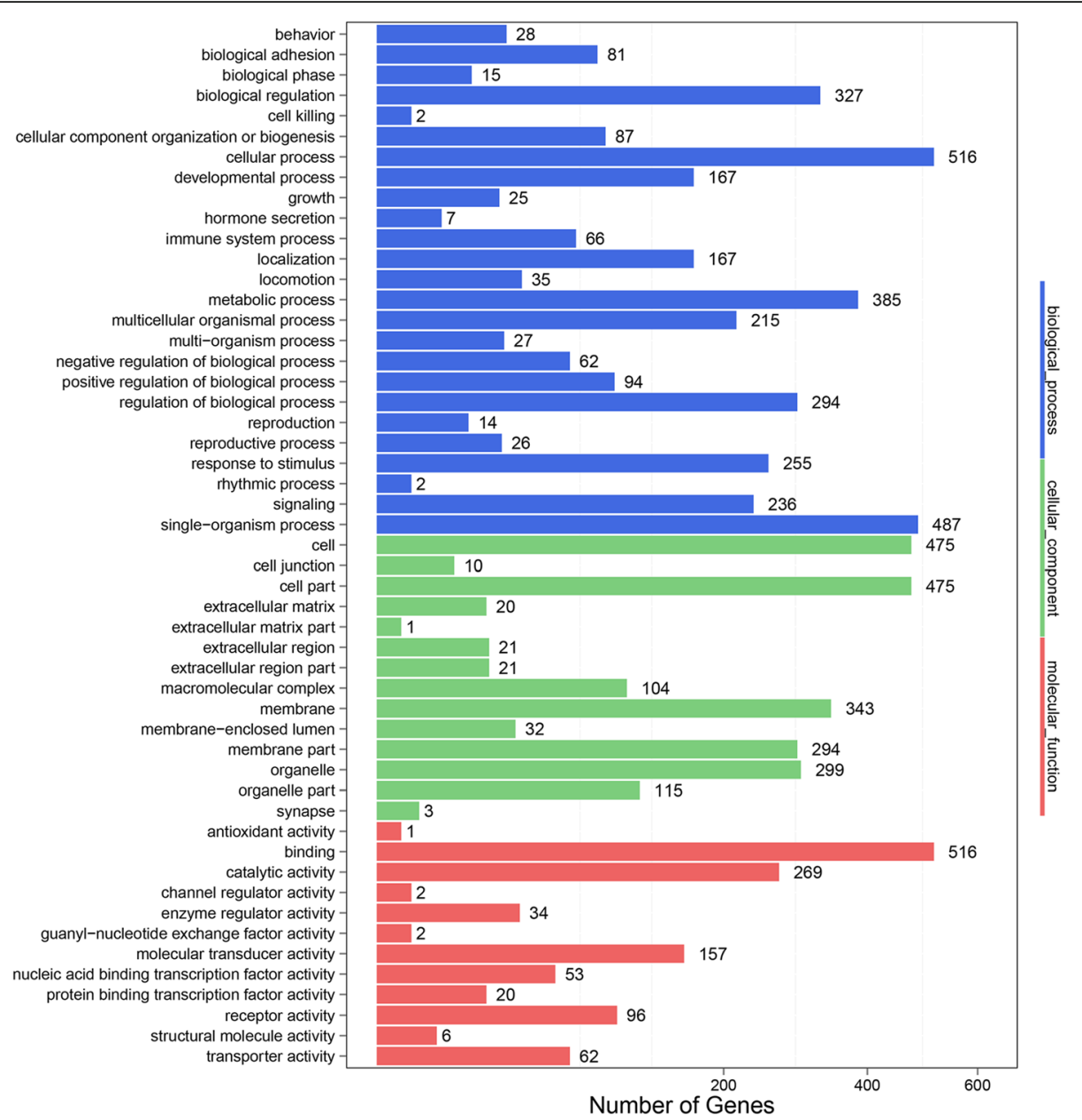

Fig. $3 \mathrm{GO}$ annotation on host targets of the viral miRNAs. The figure showed the GO annotation of these targets in biological processes, cellular components and molecular functions

end of the miRNA [39]. Thus, the stability of the "seed sequence" of viral miRNA is crucial for target-gene discrimination. We speculate that the 22 miRNAs of the identical "seed sequence" play same regulatory roles in DEV-infection. Overall, the data analysis showed that $\mathrm{CHv}$ encoded a different pattern of miRNA Compared with VAC, which might form a complex regulatory network between viral miRNAs and their target genes. The differences of miRNAs regulatory network might lead to the differential pathogenesis of these two viruses.

Studies have revealed that viral and host miRNAs play important roles in host-virus interactions [20, 22, 40]. $\mathrm{CHv}$ is a virulent herpesvirus that can mainly cause contagious lethal disease in ducks $[30,31]$ and the VAC is an avirulent virus and has been reported to encode 33 mature miRNAs from VAC-infected CEF cells [29]. However, a precise regulatory network analysis of DEV miRNAs is unlikely to be achieved without the discovery of the virulent DEV miRNAome. In this research, we collected sRNA samples from $\mathrm{CHv}$-infected DEF cells at eight time points to detect as many viral miRNAs as possible. Using High-throughput sequencing technology, we obtained 29 pre-miRNA sequences with 39 mature miRNAs from $\mathrm{CHv}$-infected DEF cells. Eight novel viral miRNAs were predicted and were confirmed by stemloop RT-qPCR (Fig. 4c). In addition, we also first made a repertoire of DEF cells miRNAs transcriptome in $\mathrm{CHv}$ infected and uninfected cells and have performed a preliminary analysis of the functions of these miRNAs. These data provide a foundation for further investigations on host-herpesvirus interactions.

Among the 8 novel viral miRNAs, the dev-miR-D275p, dev-miR-D28-3p, dev-miR-D29-5p and dev-miRD30-3p were located in coding region of UL26, UL24, UL19 and UL9 gene, respectively. The remaining four miRNAs were encoded in the in noncoding regions of $\mathrm{CHv}$ genome. Several reports revealed that most $\alpha$ herpesvirus-encoded miRNAs were found clustered in the repeat or other adjacent regions of the viral genome [20, 23-27, 41]. However, the $39 \mathrm{CHv}$-encoded miRNAs 


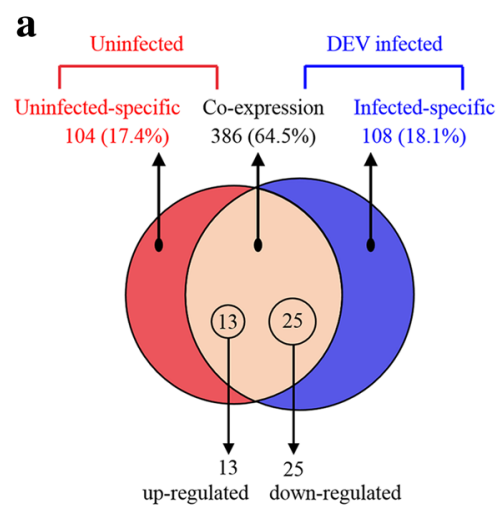

\section{c}

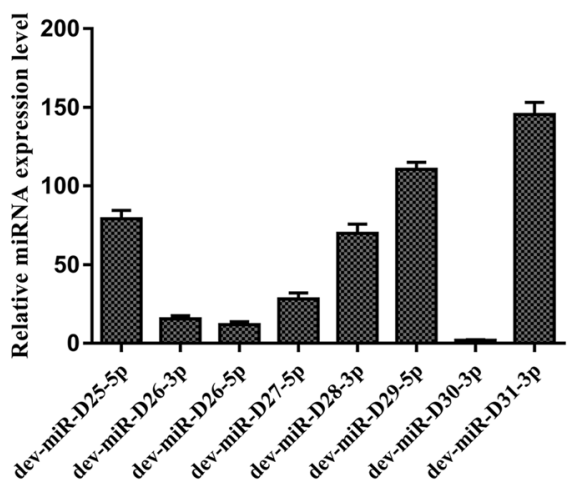

b

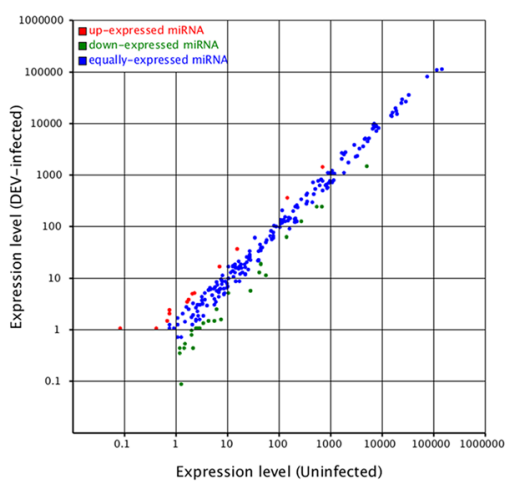

d

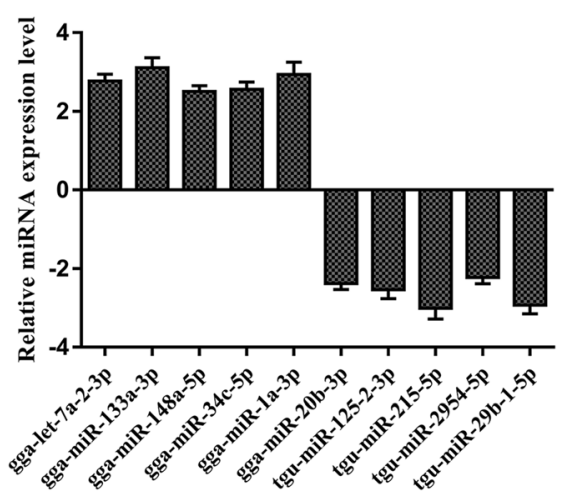

Fig. 4 Characteristics of viral and host miRNAs. a The Venn diagram shows the distribution of 598 unique miRNAs between uninfected (left, red circle) and DEV-infected sample (right, blue circle) libraries. b Differential expression of host miRNAs as a function of DEV CHv infection. Red, miRNAs with ratio $>2$ (infected/uninfected in expression); blue, miRNAs with $1 / 2 \leq$ ratio $\leq 2$; green, ratio $<1 / 2$. c Expression levels detection of 8 virus-encoded novel miRNAs using stem-loop RT-qPCR. $\mathbf{d}$ Confirmation of 10 differentially expressed host miRNAs using stem-loop RT-qPCR

were distributed mostly in the unique long region (UL) and the repeat region (IRS and TRS) of the genome (Fig. 2). This result was consistent with the previous report about the distribution of VAC-encoded miRNAs [29]. Moreover, of the seven miRNAs detected with two copies, miR-D22b-3p, miR-D22b-5p and miR-D23b-3p were located in the coding region of ICP4 in an antisense orientation, which could theoretically lead to the cleavage of the transcript and negative regulation of the gene like siRNAs [42-46].

Several studies have confirmed that herpesvirusencoded miRNAs can target viral immediate-early (IE) genes to regulate viral latent and lytic infection [20-22]. The hsv1-miR-H2-3p and hsv1-miR-H6 target the ICP0 and ICP4 genes of HSV-1 respectively [47], the hsv2miR-H2-3 target the ICP0 gene of HSV-2 [46, 48], the mdv1-miR-M7-5P target the ICP4 and ICP27 genes of MDV-1 [49] and the litv-miR-I5 target the ICP4 gene of LITV [50]. The above target genes acted as viral IE genes which upregulate early and late genes of herpesvirus subfamilies and downregulate latency-associated transcript (LAT), inducing the virus towards lytic infection [20, 21]. The targeting of IE genes by viral miRNAs was thought to inhibit entry into viral replication and maintain the latent infection state [22]. In our study, dev-miR-D4-3p, dev-miR-D11-3p, and dev-miRD20-5p were predicted to target the 3'UTR region of the CHv ICP4 gene. Dev-miR-D1-5p, dev-miR-D8-3p, devmiR-D12-5p, dev-miR-D17-3p, dev-miR-D26-3p, devmiR-D28-3p and dev-miR-D30-3p were predicted to target the 3'UTR region of the CHv US1 gene. Our results confirmed that dev-miR-D8-3p could directly target the 3'-UTR of the US1 gene. Dev-miR-D13-5p and dev-miR-D14-3p are predicted to target the 3'UTR region of the CHv UL54 gene (Additional file 4: Figure S2b). The ICP4, US1 and UL54 of CHv were considered the functional equivalent of the immediate-early (IE) genes ICP4, ICP22 and ICP27 of HSV-1 [7, 30, 51, 52]. Thus, we speculate that these viral miRNAs may play key roles in the regulation of the $\mathrm{CHv}$ lytic and latent infection.

Some virus-encoded miRNAs could regulate the cellular signal pathway to evade the immune response. For example, the hcmv-miR-UL112-3p was reported to 


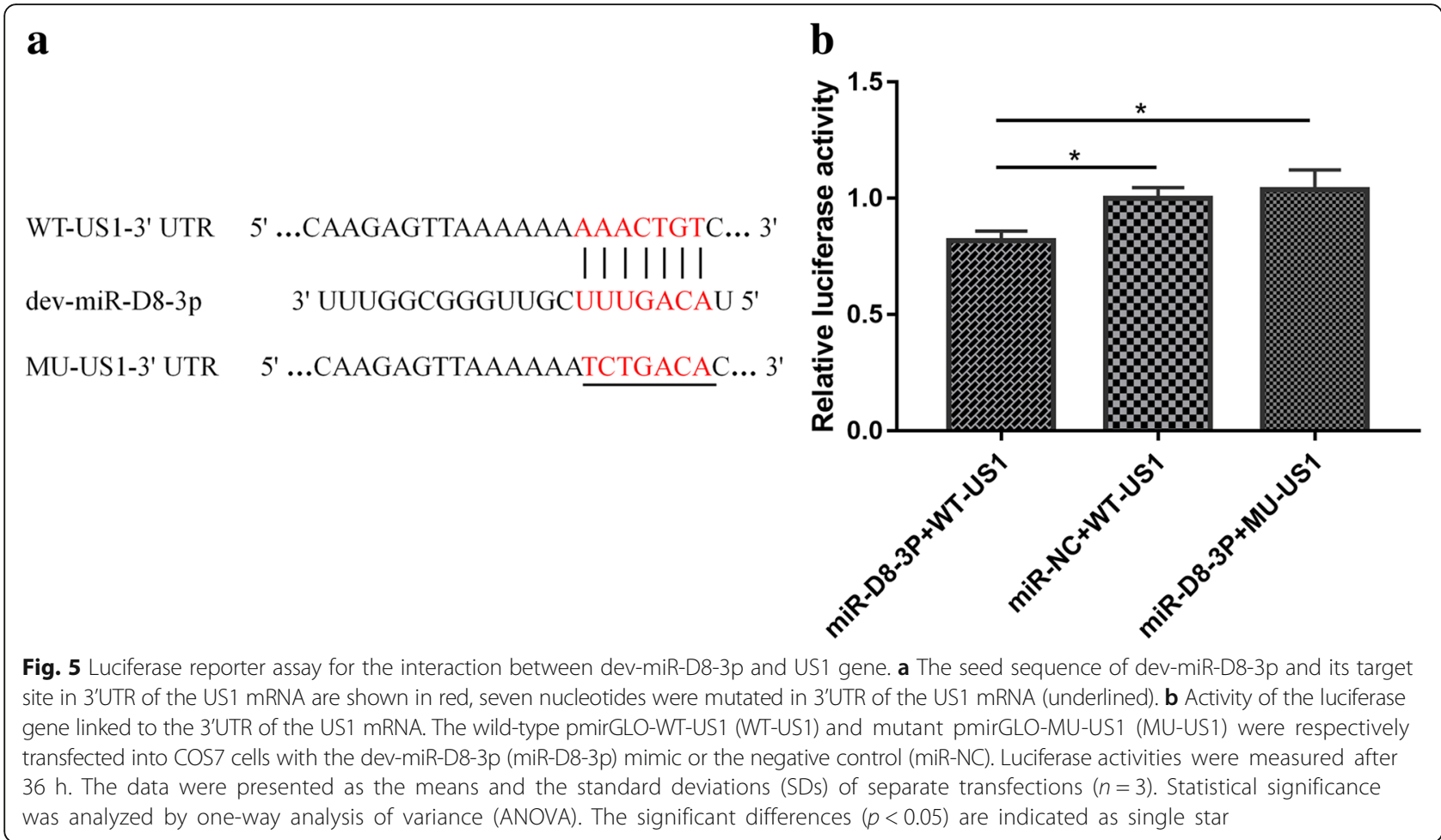

target toll-like receptors 2 (TLR2), inhibiting IRAK1/ $\mathrm{NF} \kappa \mathrm{B}$ signaling and avoiding the related inflammatory response [53]. The mdv1-miR-M4-5P regulated the endogenous TLR3 gene that repressed IFN- $\beta$ production expression and facilitates virus replication [54]. Three virus-encoded miRNAs (e.g., hcmv-miR-UL112-1, ebvmiR-BART2-5p and kshv-miR-K12-7) could repress identical target gene MICB and lead to a similar outcome, evading NK cell recognition and immune response [55]. The kshv-miR-K12-9 and kshv-miR-K12-5 could target IRAK1 and MYD88, respectively, which repressed TLR/IL-1R signaling, resulting in reduced inflammation [56]. The kshv-miR-K12-11 could target IkB kinase epsilon $(\mathrm{IKK} \varepsilon)$, inhibiting type I interferon signal pathway [57]. Moreover, viral miRNAs could regulate cell growth and survival to favour viral replication. For example, kshv-miR-K12-10 could inhibit TWEAKinduced apoptosis by targeting the cellular TWEAKR [4], which contributed to cell survival. In addition, mdv1-miR-M4-5p could target LTBP1, which suppressed the TGF- $\beta$ signaling [58]. Kshv-miR-K12-11 targeted SMAD5 which interfered with the TGF- $\beta$ pathway [59]. The suppression of TGF- $\beta$ signaling ultimately result in increased cell survival and virally induced oncogenesis $[58,59]$. In our study, GO analysis on the cellular targets of viral miRNAs showed that these targets were involved in complex cellular processes, including signal-organism processes, the metabolic pathway, biological regulation, immune response and signaling process.
The virus could alter host miRNA expression profiles to favour viral replication. In our study, 38 cellular miRNAs were expressed differentially in both the $\mathrm{CHv}$ infected library and mock library. These dysregulated host miRNAs were identified to play crucial roles in other viral infections. For example, miR-let-7a was downregulated in NPC cells after EBV-infection, which in turn promoted viral replication by targeting the dicer gene [60]. The gga-miR-26a was downregulated in MDV-infected spleens at cytolytic infection, latency and tumour transformation phases. Decreasing the expression of gga-miR-26a had been shown to contribute to MDV-induced lymphomagenesis upon regulation of NEK6 proteins [61]. The previous research showed that the differential expression of gga-miR-181a contributed to MDV-induced lymphomagenesis by targeting IGF2BP3/MYBL1 genes [62]. Cellular microRNA miR$181 \mathrm{~b}$ inhibited replication of mink enteritis virus (MEV) by repression of non-structural protein 1(NS1) translation [63]. The gga-miR-15b was downregulated in splenic tumours after MDV infection and had a negative effect on the expression of ATF2, facilitating viral replication by increasing the expression of the ATF2 [64]. Expression of miR-146 was upregulated after EBV infection, which could downregulate levels of IRAK1 and TRAF6 proteins, reducing the activity of host immune and inflammatory response [65]. Recently, miR148 was reported as a novel biomarker in non-small-cell lung cancer screening [66]. In our prediction results, 
miR-148a-5p could target UL1, UL2 UL3, UL24 and UL25 genes of CHv. MiR-181a-3p could target UL24, UL54, US3, US5 and US8 genes of $\mathrm{CHv}$ (Additional file 10: Figure S3a). The ICP4 gene of $\mathrm{CHv}$ was targeted by miR-135a-1-3p and miR-135a-2-3p, while the UL54 gene was targeted by miR-124a-3p, miR-135a-13p, miR-135a-2-3p, miR-15b-3p, miR-181a-3p and miR-181b-1-3p. A complex regulatory network was formed between 36 differentially expressed host miRNAs and their 40 viral target genes (Additional file 10: Figure S3b). However, the regulatory functions of these dysregulated cellular miRNAs in the process of $\mathrm{CHv}$ replication need further analysis.

\section{Conclusion}

In this study, we obtained 39 DEV-encoded miRNAs from $\mathrm{CHv}$-infected DEF cells by high-throughput sequencing. Of these, 8 novel viral miRNAs were detected and confirmed through stem-loop RT-qPCR. Conservative analysis showed that $\mathrm{CHv}$ encoded a different set of miRNAs and formed a unique regulatory network compared with VAC. In addition, a total of 598 novel duckencoded miRNAs were detected by aligning with known mature miRNAs of Gallus gallus and Taeniopygia guttata. This is the first report of a DEF miRNA expression profile and an analysis of these miRNAs regulatory mechanisms during DEV infection.

\section{Additional files}

Additional file 1: Table S1. Primers used to amplify virus and host miRNAs by stem-loop RT-qPCR. Stem-loop RT-qPCR was conducted using miRNA specific stem-loop RT primers together with corresponding miRNA specific forward (F) primers and universal reverse (UR) primer. (DOCX $15 \mathrm{~kb}$ )

Additional file 2: Table S2. Distribution of sRNAs in DEV-infected and uninfected samples. (DOCX $15 \mathrm{~kb}$ )

Additional File 3: The expression profiling of $\mathrm{CHv}$ miRNAs and premiRNA secondary structures. MiRNA sequences and their coresponding reads mapped on the precursors of $\mathrm{CHv}$ miRNA genes. Opening parentheses indicate pairing nucleotides. Inside the closed parentheses indicate the minimum free energy for the secondary structure of the miRNA. The number of reads mapped to the miRNA precursors is indicated in the right side. Mature miRNAs are denoted in red. The hairpin structures of pre-miRNA is shown at the back. (PDF $649 \mathrm{~kb}$ )

Additional File 4: Figure S2. Regulatory network of $\mathrm{CHv}$-encoded miRNAs and $\mathrm{CHv}$ genes. a Gene regulatory network formed by $\mathrm{CHv}$-encoded miRNAs (red ellipses) and their target genes (yellow ectangles). b Gene regulatory network of $\mathrm{CHv}$-encoded miRNAs (red ellipses) and their target immediate-early(IE) genes (yellow rectangles) (PDF 401 kb)

Additional file 5: Table S3. Predicted host target genes of DEV miRNAs. Host target genes were predicted using PITA and RNAhybrid software. (XLSX $832 \mathrm{~kb}$ )

Additional file 6: Table S4. Gene ontology analysis on host targets of the viral miRNAs (XLSX $23 \mathrm{~kb}$ )

Additional file 7: Table S5. Novel duck miRNA expressed in DEF cells. The 386 mature sequence and sequence read count of novel duck miRNAs predicted with miRDeep in each sequenced sample of DEF cells. (XLSX $26 \mathrm{~kb})$
Additional file 8: Table S6. Novel duck miRNA expressed in DEF cells. The 212 mature sequence and sequence read count of novel duck miRNAs predicted with miRDeep in each sequenced sample of DEF cells. (XLSX $15 \mathrm{~kb}$ )

Additional file 9: Table S7. Differentially expressed host alignment miRNA in CHv-infected DEF cells. Fold-change $=\log 2$ (infected $/$ mock in expression) $>1$ or $<-1$, and $p$-value $<0.05$ indicated significance differentially expressed miRNA. Fold-change $<-1$ indicates downregulated, Fold-change $>1$ indicates up-regulated. (XLSX $12 \mathrm{~kb}$ )

Additional File 10: Figure S3. Regulatory network of DEF miRNAs and $\mathrm{CHv}$ genes. a Gene regulatory network formed by differentially-expressed DEF miRNAs (blue ellipses) and their target genes (yellow rectangles). $\mathbf{b}$ Gene regulatory network of differentially-expressed DEF miRNAs (blue circles) and target immediate-early (IE) genes (yellow rectangles). (PDF 353 kb)

\section{Abbreviations}

CHv: Chinese virulent; DEV: Duck enteritis virus; HCMV: Human

Cytomegalovirus; HSV-1: Herpes simplex virus 1; HSV-2: Herpes simplex virus 2; IRS: Inverted repeated sequences; IRS: Inverted repeated sequences; MDV1: Marek's disease virus 1; MDV-2: Marek's disease virus 2; PRV: Pseudorabies virus; RT-qPCR: Real-time quantitative reverse transcriotion PCR; TRS: terminal repeated sequences; UL: Unique long region; UL: Unique long region; US: Unique short; US: Unique short region; VAC: vaccine

\section{Acknowledgements}

We would like to thank Jue Wang (BGl Genomics Co, Ltd., China) for technical assistance.

\section{Funding}

This work was supported by National Science and Technology Support Program (2015BAD12B05), Integration and Demonstration of Key Technologies for Duck Industrial in Sichuan Province (2014NZ0030), China Agricultural Research System (CARS-43-8), and Sichuan Province Research Programs (2017JY0014/2014-002).

\section{Availability of data and materials}

The datasets used or analysed during this study are included within the article.

\section{Authors' contributions}

Conceived and designed the experiments: RYJ XLW. Performed the experiments: XLW, JKZ. Analyzed the data: RYJ, MSW, SC, MFL, DKZ, XXZ, KFS, ZQY, XYC, JW, ACC. Contributed reagents and materials: QY, YW. Wrote the paper: XLW, RYJ. All authors read and approved the final manuscript.

Ethics approval and consent to participate

The study was approved by the Animal Ethics Committee of Sichuan Agricultural University (approval No. XF2014-18).

Competing interests

The authors declare that they have no competing interests.

\section{Publisher's Note}

Springer Nature remains neutral with regard to jurisdictional claims in published maps and institutional affiliations.

\section{Author details}

${ }^{1}$ Research Center of Avian Disease, College of Veterinary, Medicine of Sichuan Agricultural University, Wenjiang District, Chengdu 611130, Sichuan Province, China. ${ }^{2}$ Key Laboratory of Animal Disease and Human Health of Sichuan Province, Wenjiang District, Chengdu 611130, Sichuan Province, China. Institute of Preventive Veterinary Medicine, Sichuan Agricultural University, Wenjiang District, Chengdu 611130, Sichuan Province, China. ${ }^{4}$ BGI Genomics Co,shenzhen Ltd, Shenzhen 518083, Guangdong Province, China. 


\section{Received: 1 December 2017 Accepted: 20 April 2018}

\section{Published online: 28 April 2018}

\section{References}

1. Metwally SA SD, Glisson JR, McDougald LR, Nolan, LK, Suarez DL, Nair $\checkmark$. Duck Virus Enteritis (Duck Plague). In: Dis poultry, 13th edition 2013: 431-440.

2. Converse KA, Kidd GA. Duck plague epizootics in the United States, 19671995. J Wildl Dis. 2001;37(2):347-57.

3. Kaleta EF, Kuczka A, Kühnhold A, Bunzenthal C, Bönner BM, Hanka K, et al. Outbreak of duck plague (duck herpesvirus enteritis) in numerous species of captive ducks and geese in temporal conjunction with enforced biosecurity (in-house keeping) due to the threat of avian influenza a virus of the subtype Asia H5N1. Dtw. Dtsch Tierarztl Wochenschr. 2007;114(1):3-11.

4. Abend JR, Uldrick T, Ziegelbauer JM. Regulation of tumor necrosis factor-like weak inducer of apoptosis receptor protein (TWEAKR) expression by Kaposi's sarcoma-associated herpesvirus MicroRNA prevents TWEAK-induced apoptosis and inflammatory cytokine expression. J Virol. 2010;84(23):12139-51.

5. King AMQ. Virus taxonomy: classification and nomenclature of viruses: ninth report of the international committee on taxonomy of viruses: Elsevier/ academic press; 2012.

6. Wang G, Qu Y, Wang F, Hu D, Liu L, Li N, et al. The comprehensive diagnosis and prevention of duck plague in Northwest Shandong province of China. Poultry Sci. 2013;92(11):2892-8.

7. Li Y, Huang B, Ma X, Wu J, Li F, Ai W, et al. Molecular characterization of the genome of duck enteritis virus. Virology. 2009;391(2):151-61.

8. Wang J, Höper D, Beer M, Osterrieder N. Complete genome sequence of virulent duck enteritis virus (DEV) strain 2085 and comparison with genome sequences of virulent and attenuated DEV strains. Virus Res. 2011;160(1): $316-25$.

9. Bartel DP. MicroRNAs: genomics, biogenesis, mechanism, and function. Cell. 2004;116(2):281-97.

10. Boss IW, Plaisance KB, Renne R. Role of virus-encoded microRNAs in herpesvirus biology. Trends in Microbiol. 2009;17(12):544-53.

11. Alvarezgarcia I, Miska EA. MicroRNA functions in animal development and human disease. Develop. 2005;132(21):4653-62.

12. Cullen BR. Viral and cellular messenger RNA targets of viral microRNAs. Nature. 2009;457(7228):421-5.

13. Chen Z, Zeng H, Guo Y, Liu P, Pan H. Deng a, et al. miRNA-145 inhibits nonsmall cell lung cancer cell proliferation by targeting c-Myc. J Experi \& Clin Cancer Res. 2010;29(1):1-10.

14. Huang $\mathrm{S}, \mathrm{He} X$. The role of microRNAs in liver cancer progression. Bri. J Cancer. 2011;104(2):235-40.

15. Kincaid RP, Sullivan CS. Virus-encoded microRNAs: an overview and a look to the future. PLoS Pathog. 2012;8(12):e1003018.

16. Chen CJ, Cox JE, Kincaid RP, Martinez A, Sullivan CS. Divergent MicroRNA Targetomes of closely related circulating strains of a polyomavirus. J Virol. 2013:87(20):11135-47.

17. Yao $Y$, Smith LP, Nair $V$, Watson M. An avian retrovirus uses canonical expression and processing mechanisms to generate viral microRNA. J Virol. 2014;88(1):2-9

18. Kincaid RP, Burke JM, Cox JC, Villiers EMD, Sullivan CS. A human torque Teno virus encodes a MicroRNA that inhibits interferon signaling. PLoS Pathog. 2013:9(12):e1003818.

19. Kozomara A, Griffithsjones S. miRBase: annotating high confidence microRNAs using deep sequencing data. Nucleic Acids Res. 2014;42:68-73.

20. Yao $Y$, Nair $V$. Role of virus-encoded microRNAs in avian viral diseases. Viruses. 2014;6(3):1379-94.

21. Piedade D, Azevedo-pereira JM. The role of microRNAs in the pathogenesis of herpesvirus infection. Viruses. 2016;8(6):156.

22. Grey F. Role of microRNAs in herpesvirus latency and persistence. J Gen Virol. 2015;96(4):739-51.

23. Burnside J, Bernberg E, Anderson A, Lu C, Meyers BC, Green PJ, et al. Marek's disease virus encodes MicroRNAs that map to meq and the latencyassociated transcript. J Virol. 2006:80(17):8778-86.

24. Yao $Y$, Zhao $Y, X u H$, Smith LP, Lawrie $C H$, Watson $M$, et al. MicroRNA profile of Marek's disease virus-transformed T-cell line MSB-1: predominance of virus-encoded microRNAs. J Virol. 2008;82(8):4007-15.
25. Yao Y, Zhao Y, Xu H, Smith LP, Lawrie CH, Sewer A, et al. Marek's disease virus type 2 (MDV-2)-encoded microRNAs show no sequence conservation with those encoded by MDV-1. J Virol. 2007;81(13):7164-70.

26. Waidner LA, Morgan RW, Anderson AS, Bernberg EL, Kamboj S, Garcia M, et al. MicroRNAs of Gallid and Meleagrid herpesviruses show generally conserved genomic locations and are virus-specific. Virology. 2009;388(1): 128-36.

27. Yao YX, Zhao YG, Smith LP, Watson M, Nair V. Novel microRNAs (miRNAs) encoded by herpesvirus of turkeys: evidence of miRNA evolution by duplication. J Virol. 2009;83(13):6969-73.

28. Rachamadugu R, Lee JY, Wooming A, Kong BW. Identification and expression analysis of infectious laryngotracheitis virus encoding microRNAs. Virus Genes. 2009:39(3):301-8.

29. Yao $Y$, Smith LP, Petherbridge L, Watson M, Nair V. Novel microRNAs encoded by duck enteritis virus. J Gen Virol. 2012;93(7):1530-6.

30. Wu Y, Cheng A, Wang M, Yang Q, Zhu D, Jia R, et al. Complete genomic sequence of Chinese virulent duck enteritis virus. J Virol. 2012;86(10):5965.

31. Wu Y, Cheng A, Wang M, Zhu D, Jia R, Chen S, et al. Comparative genomic analysis of duck enteritis virus strains. J Virol. 2012;86(24):13841-2.

32. Liu X, Liao S, Xu Z, Zhu L, Yang F, Guo W. Identification and analysis of the porcine MicroRNA in porcine cytomegalovirus-infected macrophages using deep sequencing. PLoS One. 2016;11(3):e0150971.

33. Liu X, Zhu L, Liao S, Xu Z, Zhou Y. The porcine microRNA transcriptome response to transmissible gastroenteritis virus infection. PLoS One. 2015; 10(3):e0120377.

34. Langmead B, Trapnell C, Pop M, Salzberg SL. Ultrafast and memory-efficient alignment of short DNA sequences to the human genome. Genome Biol. 2009:10(3):R25.

35. Audic S, Claverie JM. The significance of digital gene expression profiles. Genome Res. 1997;7(10):986-95.

36. Liu F, Zheng H, Tong W, Li GX, Tian Q, Liang C, et al. Identification and analysis of novel viral and host dysregulated MicroRNAs in variant pseudorabies virus-infected PK15 cells. PLoS One. 2016;11(3):e0151546.

37. Young MD, Wakeeld MJ. Smyth GK. Oshlack A. goseq: Gene Ontology testing for RNA-seq datasets; 2012.

38. Varkonyi-Gasic E, Hellens RP. Quantitative stem-loop RT-PCR for detection of microRNAs. Meth mole. Biol. 2011;744(9):145-57.

39. Bartel DP. MicroRNA target recognition and regulatory functions. Cell. 2009; 136(2):215-33.

40. Frappier $\mathrm{L}$. Regulation of herpesvirus reactivation by host microRNAs. J Virol. 2015;89(5):2456

41. Morgan R, Anderson A, Bernberg E, Kamboj S, Huang E, Lagasse G, et al. Sequence conservation and differential expression of Marek's disease virus microRNAs. J Virol. 2008;82(24):12213-20.

42. Barth S, Pfuhl T, Mamiani A, Ehses C, Roemer K, Kremmer E, et al. EpsteinBarr virus-encoded microRNA miR-BART2 down-regulates the viral DNA polymerase BALF5. Nucleic Acids Res. 2008:36(2):666-75.

43. Seo GJ, Fink LH, O'Hara B, Atwood WJ, Sullivan CS. Evolutionarily conserved function of a viral microRNA. J Virol. 2008:82(20):9823-8.

44. Seo GJ, Chen CJ, Sullivan CS. Merkel cell polyomavirus encodes a microRNA with the ability to autoregulate viral gene expression. Virology. 2009;383(2): 183-7.

45. Tang S, Bertke AS, Patel A, Wang K, Cohen Jl, Krause PR. An acutely and latently expressed herpes simplex virus 2 viral microRNA inhibits expression of ICP34.5, a viral neurovirulence factor. Proc Natl Acad Sci U S A. 2008; 105(31):10931-6.

46. Shuang Tang AP, Krause PR. Novel less-abundant viral MicroRNAs encoded by herpes simplex virus 2 latency-associated transcript and their roles in regulating ICP34.5 and ICP0 mRNAs. J Virol. 2009;83(3):1433-42.

47. Umbach JL, Kramer MF, Jurak I, Karnowski HW, Coen DM, Cullen BR. MicroRNAs expressed by herpes simplex virus 1 during latent infection regulate viral mRNAs. Nature. 2008:454(7205):780-3.

48. Tang S, Bertke AS, Patel A, Margolis TP, Krause PR. Herpes simplex virus 2 MicroRNA miR-H6 is a novel latency-associated transcript-associated MicroRNA, but reduction of its expression does not influence the establishment of viral latency or the recurrence phenotype. J Virol. 2011; 85(9):4501-9.

49. Strassheim S, Stik G, Rasschaert D, Laurent S. mdv1-miR-M7-5p, located in the newly identified first intron of the latency-associated transcript of Marek's disease virus, targets the immediate-early genes ICP4 and ICP27. J Gen Virol. 2012;93(8):1731-42. 
50. Waidner LA, Burnside J, Anderson AS, Bernberg EL, German MA, Meyers BC, et al. A microRNA of infectious laryngotracheitis virus can downregulate and direct cleavage of ICP4 mRNA. Virology. 2011;411(1):25-31.

51. Brehm M, Samaniego LA, Bonneau RH, Deluca NA, Tevethia SS. Immunogenicity of herpes simplex virus type 1 mutants containing deletions in one or more a-genes: ICP4, ICP27, ICP22, and ICP0. Virology. 1999;256(2):258-69.

52. Liu C, Cheng A, Wang M, Chen S, Jia R, Zhu D, et al. Duck enteritis virus UL54 is an IE protein primarily located in the nucleus. Virol J. 2015;12(1):1-8.

53. Landais I, Pelton C, Streblow D, Defilippis V, Mcweeney S, Nelson JA. Human cytomegalovirus miR-UL112-3p targets TLR2 and modulates the TLR2/ IRAK1/NFKB signaling pathway. PLoS Pathog. 2015;11(5):e1004881.

54. Hu X, Ye J, Qin A, Zou H, Shao H, Qian K. Both MicroRNA-155 and virusencoded MiR-155 Ortholog regulate TLR3 expression. PLoS One. 2015;10(5): e0126012.

55. Stern-Ginossar N, Elefant N, Zimmermann A, Wolf DG, Saleh N, Biton M, et al. Host immune system gene targeting by a viral miRNA. Science. 2007; 317(5836):376-81.

56. Abend JR, Ramalingam D, Kieffer-Kwon P, Uldrick TS, Yarchoan R, Ziegelbauer JM. Kaposi's sarcoma-associated herpesvirus MicroRNAs target IRAK1 and MYD88, two components of the toll-like receptor/interleukin-1R signaling Cascade, to reduce inflammatory-cytokine expression. J Virol. 2012; 86(21):11663-74

57. Liang D, Gao Y, Lin X, He Z, Zhao Q, Deng Q, et al. A human herpesvirus miRNA attenuates interferon signaling and contributes to maintenance of viral latency by targeting IKKE. Cell Res. 2011;21(5):793-806.

58. Chi JQ, Teng M, Yu ZH, Xu H, Su JW, Zhao P, et al. Marek's disease virusencoded analog of microRNA-155 activates the oncogene c-Myc by targeting LTBP1 and suppressing the TGF- $\beta$ signaling pathway. Virology. 2015:476:72-84.

59. Yunhua L, Rui S, Xianzhi L, Deguang L, Qiang D, Ke L. Kaposi's sarcomaassociated herpesvirus-encoded microRNA miR-K12-11 attenuates transforming growth factor beta signaling through suppression of SMAD5. $J$ Virol. 2012;86(3):1372-81.

60. Mansouri S, Pan Q, Blencowe BJ, Claycomb JM, Frappier L. Epstein-Barr virus EBNA1 protein regulates viral latency through effects on let-7 microRNA and dicer. J Virol. 2014;88(19):11166-77.

61. Li X, Lian L, Zhang D, Qu L, Yang N. Gga-miR-26a targets NEK6 and suppresses Marek's disease lymphoma cell proliferation. Poultry Sci. 2014; 93(5):1097-105.

62. Lian L. Qu L, Chen Y, Lamont SJ, Yang N, Lian L, et al. a systematic analysis of miRNA transcriptome in Marek's disease virus-induced lymphoma reveals novel and differentially expressed miRNAs. PLoS One. 2011;7(11):e51003.

63. Sun JZ, Wang J, Yuan D, Wang S, Li Z, Yi B, et al. Cellular microRNA miR$181 \mathrm{~b}$ inhibits replication of mink enteritis virus by repression of nonstructural protein 1 translation. PLoS One. 2013;8(12):e81515.

64. Tian F, Luo J, Zhang H, Chang S, Song J. MiRNA expression signatures induced by Marek's disease virus infection in chickens. Genomics. 2012; 99(3):152-9.

65. Taganov KD, Boldin MP, Chang KJ, Baltimore D. NF-kappaB-dependent induction of microRNA miR-146, an inhibitor targeted to signaling proteins of innate immune responses. Proc Natl Acad Sci U S A. 2006;103(33):12481-6.

66. Yang JS, Li BJ, Lu HW, Chen Y, Lu C, Zhu RX, et al. Serum miR-152, miR148a, miR-148b, and miR-21 as novel biomarkers in non-small cell lung cancer screening. Tumour Biology the Journal of the International Society for Oncodevelopmental Biology \& Medicine. 2014;36(4):3035-42.

\section{Ready to submit your research? Choose BMC and benefit from:}

- fast, convenient online submission

- thorough peer review by experienced researchers in your field

- rapid publication on acceptance

- support for research data, including large and complex data types

- gold Open Access which fosters wider collaboration and increased citations

- maximum visibility for your research: over $100 \mathrm{M}$ website views per year

At BMC, research is always in progress.

Learn more biomedcentral.com/submissions 